\title{
Pattern of using social networks to obtain information related to COVID-19 in Iranian students
}

\author{
Poorandokht Afshari ${ }^{1}$, Maryam Beheshtinasab², Maria Cheraghi³ \\ ${ }^{1}$ Menopause Andropause Research Center, Ahvaz Jundishapur University of Medical Sciences, Ahvaz, Iran \\ 2Department of Midwifery, School of Nursing and Midwifery, Ahvaz Jundishapur University of Medical Sciences, Ahvaz, Iran \\ ${ }^{3}$ Social Determinant of Health Research Center, Department of Public Health, School of Health, Ahvaz Jundishapur University \\ of Medical Sciences, Ahvaz, Iran
}

Neuropsychiatria i Neuropsychologia 2021; 16, 1-2: 17-23

Address for correspondence:

Maria Cheraghi, PhD

Social Determinate of Health Research Center

Ahvaz Jundishapur University of Medical Sciences

Iran

e-mail: mariacheraghi@gmail.com

\section{Abstract}

Introduction: We aimed to evaluate use of social media during the coronavirus pandemic as a source of information about COVID-19 by students.

Material and methods: This was a web-based study, in which the frequency and type of virtual social media used by students as a source of information about COVID-19 were evaluated by the available sampling method. The statistical population of the study consisted of 500 students of medical universities in Iran. In the first step, administrators of student groups across the country were identified and contacted and asked to assist the research team by placing a link to complete the questionnaire, after which students voluntarily completed the online questionnaire in a self-reporting manner.

Results: The mean age of participants was $31.29 \pm 10.8$ years. The selection percentages based on the number of selections were: WhatsApp (35.2), Instagram (32.7), Telegram (21.2), Facebook (8.3) and other networks (2.6). Regarding the relationship between the educational level $(p<0.001)$ and the field of study $(p<0.01)$, a statistically significant difference was found for the question of which media information is more acceptable in relation to obtaining information related to COVID-19.

Conclusions: It was found that social media will enable these media to act as a powerful tool to change the behavior of people and promote the well-being of individuals and public health. Social media is very important in combating this contagious disease, not only to obtain information and update on it, but also to understand how it spreads, how people function and how to respond to it.

Key words: social networks, COVID-19, students, Iran.

\section{Introduction}

The term 'social network' was first used in 1945 by G.E. Barnes. He used the term to describe the study of rural social ties in Norway (Taghvaei Yazdi i Chitsaz 2016). Social networks can affect people's health in different ways. However, this effect can be an operating paradox, as sometimes obtaining health information from social networks helps in treatment of the disease, and sometimes recommendations without research support for diseases in these networks can be harmful. Many healthcare providers around the world work on social networks such as Skype, WhatsApp, Twitter, Facebook, YouTube and personal blogs (Nikbakht-Nasrabadi et al. 2019). Today, there is no doubt that the use of social media in academic communication has improved the level of scientific transparency in universities and accelerates the exchange of information and increases the level of efficiency and trust among professionals (Samiei 2015). Global access to the Internet was well established during the SARS epidemic, but access to potential medical users was largely dependent on contact by email and personal communication. Using free open access medical education, good examples of the effectiveness of open access to information have been provided (Chan et al. 2020). With the outbreak of COVID-19, national, state, and government preventive measures affected the daily lives of millions of people. People around the world are largely using "social distancing" to prevent the disease. This has led to social interactions 
moving online, and with the continuation of the COVID-19 pandemic, more people seem to be turning to social media (Chen 2020). In the event of a natural disaster, people are more likely to share posts from users who are eyewitnesses to the event and are close to the event. In addition, dependencies and perceptions of people can also affect the information sharing behavior of users (Lifang et al. 2020). Virtual social media provide the best tool, space, opportunity and use of all their facilities to increase self-care. Professors of medical sciences also have various socio-cultural responsibilities, and this means that the professor should also be socially responsive to the health needs of the people. Advances in technology have made it easy for faculty members to connect with the community around them (far or near), and the professor can go beyond the classroom or the bed and communicate with people (Mahasti Jouybari 2014). In China, it was important to use social media wisely during widespread community quarantine because social media provides an opportunity to communicate the reasons for quarantine, and also provide reassurance and practical advice to prevent rumors and panic. Digital technologies can overcome remote social barriers during mass quarantine and provide resources for mental health support and solidarity with those in a state of disarray (Depoux et al. 2020).

The role of internet monitoring tools in the early forecasting of epidemic diseases, including influenza, H1N1 dengue fever, Zika, measles, MERS and COVID-19 (Zareie et al. 2021), has already been reported. The availability of basic information about infectious diseases through Internet search engines and social media will be useful for decisions related to disease control and prevention (Cuilian et al. 2020). Officials in Vietnam stated that despite their proximity to China, the proper use of social media, scanning and collecting official media news related to COVID-19 had helped control the disease between early January and April $4^{\text {th }}$ (Viet-Phuong et al. 2020). In more than half a percent of cases, those were using social networks to get new information in field of health, and based on the types of applications which has used in social networks, by some terms of access to the most users of health professionals were health care providers or health care recipients, and in addition have educational and research applications and information flow is another application that includes the steps of collection, storage, processing, retrieval, dissemination and application (Hadiseh et al. 2016). The results of the study of Fisher and Clayton (2012) indicated increasing acceptance of patients through social media in the health care system. In addition to the many benefits, the media can also have negative effects in some cases. Gao et al. (2020) found that the high prevalence of mental health problems was positively associated with the use of virtual social media, often during the outbreak of COVID-19. Dastjerdi et al. (2016) detected a significant inverse relationship between use of the Facebook social network and social health of students. The presence of youth, especially students, in social networks in Iran varies among different cities: $52 \%$ (Dastani et al. 2016), 74.5\% (Delshadi et al. 2016), 80.2\% (Khalilai 2015).

The results of a study showed that $99.4 \%$ of students were members of social networks. The median daily use of these networks was 3 hours (Mousavi et al. 2019), and the purposes of their use were reported to vary from entertainment to scientific research (Khalilai 2015). The purpose of this study was to evaluate use of social media during the coronavirus pandemic as a source of information about COVID-19 by students.

\section{Material and methods}

This was a research and descriptive study and web-based study, in which the frequency and type of virtual social media used by students as a source of information about COVID-19 were examined. The statistical population of the study consisted of 500 students of medical and non-medical universities in Iran that were connected with student virtual networks of universities. The sampling method was available. In the first step, the administrators of student groups across the country were identified and contacted and asked to assist the research team by placing a link to complete the questionnaire, after which students voluntarily completed the online questionnaire in a self-reporting manner.

The research questionnaire was prepared to achieve the objectives of the project in two parts. The first part contained the demographic information of the participants in the research and the second part contained specialized information that during the question of using virtual media, the type of selected media, used hours and specialized use in relation to COVID-19 was obtained. The content validity method was used to determine the validity.

In this way, an information form was prepared and then provided to 11 faculty members of Ahvaz Jundishapur University of Medical Sciences, and using their opinions, the questionnaire 
Table 1. Frequency distribution of research demographic variables

\begin{tabular}{lc} 
Demographic variables & $\begin{array}{c}\text { Absolute and } \\
\text { relative frequency } \\
\text { distribution }\end{array}$ \\
Age (years) & $31.26(\mathrm{SD}=10.78)$ \\
\hline Sex & $358(71.6 \%)$ \\
\hline Female & $142(28.4 \%)$ \\
\hline Male & $198(39.6 \%)$ \\
\hline Educational level & $111(22.2 \%)$ \\
\hline BA & $191(38.2 \%)$ \\
\hline MSc & $76(15.2 \%)$ \\
\hline MD/PhD & $181(36.2 \%)$ \\
\hline Department of Education & $116(23.2 \%)$ \\
\hline Medical & $105(21.0 \%)$ \\
\hline Paramedical & \\
\hline Technical and Engineering & \\
\hline Art & \\
\hline
\end{tabular}

was modified and completed. Reliability was determined after completion of the questionnaire by 20 students using Cronbach's $\alpha$ coefficient.

\section{Results}

The results of the study on 500 students who completed the information form showed that the mean age of participants was $31.29 \pm 10.8$. The minimum age was 19 and the maximum was 61 years, in the case of a PhD student. The majority of them were women, most of them studied in medicine and paramedical fields (Table 1), and 496 of them (99.2\%) used social media. The mean number of hours of internet use was $3.79 \pm 2.43$ per day.

The respondents were asked to select a list of 10 most used social networks. It should be noted that they could choose more than one. Finally, to calculate the most used network, the selection percentage based on the number of selections and not the number of samples, respectively, WhatsApp (35.2), Instagram (32.7), Telegram (21.2), Facebook (8.3) and other networks (2.6) were announced. The use of these networks was mentioned for the participants according to Table 2, from entertainment and communication with friends and family to commercial use and obtaining different scientific and research information.

$96.8 \%$ (485 people) used social media to obtain information about COVID-19. For 35.8\%
Table 2. Type of use of virtual media by students

\begin{tabular}{lc} 
Type of use & $\begin{array}{c}\text { Absolute and } \\
\text { relative frequency } \\
\text { of use type }\end{array}$ \\
Scientific purposes & $30(6 \%)$ \\
\hline Research purposes & $8(1.6 \%)$ \\
\hline $\begin{array}{l}\text { Communicate with family } \\
\text { and relatives }\end{array}$ & $42(8.4 \%)$ \\
\hline Social interactions and exchanges & $44(8.8 \%)$ \\
\hline Fun and entertainment & $59(11.8 \%)$ \\
\hline Use as a profession & $8(1.6 \%)$ \\
\hline A combination of these reasons & $309(61.8 \%)$ \\
\hline
\end{tabular}

(179 people) social media were the only source of information about COVID-19. Do they know their sources of information on social networks that receive information related to methods of diagnosis, treatment, prevention, mortality and complications of coronavirus infection? The response of 138 people (27.6\%) was negative and they had no knowledge of the sender of the messages. They were asked whether they used the recommendations obtained from these networks, especially in relation to prevention, and $63 \%$ answered in the affirmative.

Type of use of virtual media by students regarding COVID-19 was another question for which the answers obtained showed that the use of these media from scientific exchanges and obtaining advice, providing consulting services to buying and selling equipment related to coronavirus prevention (mask, gloves and so on) is different (Table 3).

We also questioned the comparison of trust in information obtained from virtual social media with public media, and the findings showed that $35.6 \%$ had more trust in public media such as radio and television, and $29.8 \%$ had more trust in social media. The rest of the participants considered both types of information acceptable.

The $\chi^{2}$ test showed a statistically significant relationship between the education level $(p<0.001)$ and the hours of social media use, and the mean use of students studying for a doctoral degree was 4.17 hours per day, but the relationship of this with the field of study is not significant. Also, a statistically significant positive correlation was observed between age and hours of social media use.

According to the chi-square test, the relationship between the field of study and the use of social media to obtain information about COVID-19 was significant $(p<0.001)$ and 
Table 3. Type of use of virtual media by students regarding COVID-19

\begin{tabular}{lc} 
Type of use & $\begin{array}{c}\text { Absolute and relative frequency } \\
\text { of use type }\end{array}$ \\
Receiving the latest scientific information and mortality rates & $94(18.8 \%)$ \\
\hline Receiving or providing consultancy services & $52(10.4 \%)$ \\
\hline Purchase and sale of equipment related to the prevention of coronavirus & $7(1.4 \%)$ \\
\hline Scientific reasons plus consultations and exchange of information & $261(52.2 \%)$ \\
\hline Consulting and information exchange & $72(14.6 \%)$ \\
\hline Not using virtual media in connection with the coronavirus & $14(2.85 \%)$ \\
\hline
\end{tabular}

the Tukey post hoc test showed this rate to be higher among medical students.

Regarding the relationship between the educational level $(p<0.001)$ and the field of study $(p<0.01)$, a statistically significant difference was found for the question of which media information (virtual media or public media such as television) is more acceptable in relation to obtaining information related to COVID-19. At higher levels, information from both media groups was declared acceptable, while at lower levels, information obtained from social media had gained the trust of more participants.

Regarding the impact of social media content on the fear and panic caused by the coronavirus pandemic, $59.6 \%$ of students stated that it would increase their fear and panic of the disease, $25 \%$ considered that it would reduce their panic and $15.4 \%$ considered it ineffective.
The evaluation of the association between gender, level of education, type of department of education and reason for search showed that there was a statistically significant association with gender (0.01), department of education (0.001) and reason for search (Table 4). Also, there was a statistically significant association between level of education, type of department of education and social media (Table 5).

\section{Discussion}

This study was designed and performed with the aim of evaluating how students use virtual media in connection with COVID-19. The obtained data showed that nearly $99.2 \%$ of students use virtual social media, while previous research revealed that rates had increased from $52 \%$ (Dastani et al. 2016) in 2016, $74.5 \%$ (Das-

Table 4. Association between demographic variables and type of reason of search

\begin{tabular}{|c|c|c|c|c|c|c|c|c|}
\hline Variables & Facebook & Instagram & WhatsApp & Telegram & Twitter & Skip & Multimedia & $p$-value \\
\hline \multicolumn{9}{|l|}{ Gender } \\
\hline Female & 5 & 40 & 50 & 32 & 26 & 10 & 195 & \multirow[t]{2}{*}{$<0.01$} \\
\hline Male & 0 & 18 & 33 & 15 & 9 & 5 & 62 & \\
\hline \multicolumn{9}{|l|}{ Level of education } \\
\hline $\mathrm{BSC}$ & 3 & 25 & 50 & 20 & 16 & 5 & 100 & \multirow[t]{3}{*}{$<0.04$} \\
\hline MSc & 1 & 11 & 33 & 6 & 7 & 4 & 57 & \\
\hline $\mathrm{PhD} / \mathrm{MD}$ & 1 & 22 & 29 & 21 & 12 & 6 & 100 & \\
\hline \multicolumn{9}{|l|}{$\begin{array}{l}\text { Department } \\
\text { of education }\end{array}$} \\
\hline Medicine & 0 & 8 & 11 & 2 & 5 & 2 & 48 & \multirow[t]{6}{*}{$<0.001$} \\
\hline Para medicine & 1 & 22 & 14 & 14 & 14 & 8 & 108 & \\
\hline Engineer & 1 & 9 & 29 & 12 & 7 & 4 & 53 & \\
\hline Humanities & 1 & 18 & 17 & 13 & 5 & 1 & 29 & \\
\hline Languages & 0 & 0 & 5 & 4 & 2 & 0 & 10 & \\
\hline Art & 2 & 1 & 7 & 2 & 2 & 0 & 8 & \\
\hline
\end{tabular}


Table 5. Association between demographic variables and type of social media

\begin{tabular}{|c|c|c|c|c|c|c|c|c|}
\hline Variables & $\begin{array}{l}\text { Scientific } \\
\text { purposes }\end{array}$ & $\begin{array}{l}\text { Research } \\
\text { purposes }\end{array}$ & $\begin{array}{l}\text { Communi- } \\
\text { cate with } \\
\text { family } \\
\text { and rela- } \\
\text { tives }\end{array}$ & $\begin{array}{c}\text { Social } \\
\text { interac- } \\
\text { tions and } \\
\text { exchanges }\end{array}$ & $\begin{array}{c}\text { Fun and } \\
\text { entertain- } \\
\text { ment }\end{array}$ & $\begin{array}{l}\text { Use as } \\
\text { a profes- } \\
\text { sion }\end{array}$ & $\begin{array}{l}\text { Combi- } \\
\text { nation } \\
\text { of these } \\
\text { reasons }\end{array}$ & $p$-value \\
\hline \multicolumn{9}{|l|}{ Gender } \\
\hline Female & 19 & 6 & 28 & 33 & 42 & 6 & 206 & \multirow[t]{2}{*}{0.2} \\
\hline Male & 11 & 2 & 14 & 11 & 17 & 2 & 103 & \\
\hline \multicolumn{9}{|l|}{ Level of education } \\
\hline $\mathrm{BSC}$ & 15 & 2 & 15 & 21 & 23 & 5 & 129 & \multirow[t]{3}{*}{$<0.0001$} \\
\hline$M S c$ & 8 & 5 & 13 & 5 & 12 & 2 & 67 & \\
\hline $\mathrm{PhD} / \mathrm{MD}$ & 7 & 1 & 14 & 18 & 24 & 1 & 113 & \\
\hline \multicolumn{9}{|l|}{$\begin{array}{l}\text { Department } \\
\text { of education }\end{array}$} \\
\hline Medicine & 1 & 0 & 6 & 4 & 12 & 0 & 56 & \multirow[t]{6}{*}{$<0.0001$} \\
\hline Para medicine & 10 & 4 & 12 & 16 & 18 & 0 & 129 & \\
\hline $\begin{array}{l}\text { Technical and } \\
\text { Engineer }\end{array}$ & 9 & 0 & 9 & 15 & 9 & 2 & 70 & \\
\hline Humanities & 8 & 1 & 7 & 6 & 17 & 5 & 29 & \\
\hline Languages & 1 & 0 & 6 & 2 & 1 & 0 & 11 & \\
\hline Art & 1 & 3 & 1 & 1 & 2 & 1 & 14 & \\
\hline
\end{tabular}

tani et al. 2016), 80.2\% (Khalilai 2015) up to 99.4\% in 2019 (Mousavi et al. 2019) and 99.2\% in this study, which indicates the growing use of virtual networks among students.

The reasons and types of social media used in different studies are mentioned differently. In our study, the reasons for using social media mentioned by students varied from entertainment and communication with friends and family to commercial use and obtaining different scientific and research information. The three most used social media were WhatsApp (35.2), Instagram (32.7) and Telegram (21.2). Aljuboori et al. (2020) reported the growth of the use of virtual media among Iraqi students for educational purposes, noting that there is a lot of interest and increasing use of these social media for academic purposes. Many of them did not want to use social media for commercial purposes or to obtain political information, and the students' use of social media in connection with academic studies was very encouraging and suggested that the focus should be on building these resources as a credible educational platform through the advice of stakeholders in the academic field. They considered Facebook to be the most popular medium for social communication, and described the use of YouTube in the academic field as broad (Aljuboori et al. 2020).
Meşe and Aydın (2019) also note the growing use of social media by younger generations in recent years because they offer opportunities such as content sharing, entertainment, communication, community building and learning. A survey of 549 students which included participants who had been using social media for a long time found that they were willing to use them to share content. Also, they had more friends on Facebook. $88 \%$ of the respondents in the surveyed community mostly used WhatsApp and Instagram (Meşe and Aydin 2019).

In a case study, the use of social media in the academic community was examined and the demographic characteristics of users of academic social networks, the reasons for using this service and their use of other social media were analyzed. The results showed that the users were mainly professors and doctoral students, and they were young and mostly from the social sciences and the arts and humanities. It seems there was no sex difference in the use of social networks. Users mostly used social networks to connect with other academics (Nández and Borrego 2013).

Another important point in this study was the use of social media during the COVID-19 pandemic. The results of the research indicate the important role of these media in obtaining scientific information. In 
the present study, the effect of social media content on the fear and panic caused by the coronavirus pandemic, the majority of students said that this issue increased their fear and panic about the disease. Cuilian et al. (2020) consider the role of Internet monitoring tools in early prediction of epidemic diseases.

The results of the study of Fisher and Clayton (2012) indicated increasing acceptance of patients through social media in the health care system. Gao et al. (2020) found that a high prevalence of mental health problems was positively associated with the use of virtual social media, often during the outbreak of COVID-19. Oberiri and Bahiyah (2021) investigated the publication of fake news about COVID-19 on Nigerian social media and stated that altruism is the most important predictor of fake news among Nigerians. Entertainment was not significantly associated with the sharing of fake news in this study. They suggested that when receiving news (prevention or treatment) one should consider the source of information, read beyond the headlines, review the authors, research an article by examining the dates, review the evidence to confirm sufficient facts and figures, verify fake images, find other sources and ask experts (Oberiri and Bahiyah 2021). Unfortunately, sometimes this fake news can be harmful or cause unreasonable panic. In our study, a large percentage of participants received their news from unreliable sources. The results of a survey of students of medical and medical sciences in Jordan showed that medical students mostly used social media $(83.4 \%)$ and online search engines (84.8\%) as their preferred source of information about COVID-19 and were less trustful of medical search engines (64.1\%) (Khasawneh et al. 2020). Sahni and Sharma (2020) opined that the wise and prudent use of social media will enable these media to act as a powerful tool to change the behavior of people and promote the well-being of individual and public health. Social media are very important in combating this contagious disease, not only to obtain information and update on it, but also to understand how it spreads, how people function and how to respond to it (Lima et al. 2020).

\section{Declaration}

\section{Ethics approval and consent to participate}

This study was part of a research project with the code of ethics IR.AJUMS.1399.216 (SDH9909) and was implemented with the support of the Research Deputy of Ahwaz Jundishapur University of Medical Sciences.

\section{Availability of data and materials}

The datasets used during the current study are available from the first author on reasonable request.

\section{Disclosure}

The authors declare no conflict of interest.

\section{References}

1. Aljuboori AF, Fashakh AM, Bayat O. The impacts of social media on University students in Iraq. Egyptian Informatics Journal 2020; 21: 139-144.

2. Chan AKM, Nickson CP, Rudolph JW, et al. Social media for rapid knowledge dissemination: early experience from the COVID-19 pandemic. Anaesthesia 2020; 75: 1579-1582.

3. Chen E, Lerman K, Ferrara E. \#COVID-19: a public coronavirus twitter dataset tracking social media discourse about the pandemic. JMIR Public Health and Surveillance 2020.

4. Cuilian L, Chen LJ, Chen X, et al. Retrospective analysis of the possibility of predicting the COVID-19 outbreak from Internet searches and social media data, China, 2020. Euro Surveill 2020; 25: 2000199.

5. Dastani BM, Keramati J, Poorfatemi A, Ekrami A. The role of social networks on academic achievement of Gonabad University of Medical Science' students. JMED 2016; 11: 153-160.

6. Dastjerdi NB, Davarpanah H, Esmaelli M. The relationship between use of social networks facebook and social well-being of students in Isfahan University. J Appl Soc 2016; 27: 143-156.

7. Delshadi Z, Delshadi M, Shafieian Z, Mansooria M. Survey of social networking usage and its relationship with the study status of students of Ilam universities 2015. Rahavard Salamat Journal 2016; 2.

8. Depoux A, Martin S, Karafillakis E, et al. The pandemic of social media panic travels faster than the COVID-19 outbreak. J Travel Med 2020; 27: taaa031.

9. Fisher J, Clayton M. Who gives a tweet: assessing patients' interest in the use of social media for health care. Worldviews Evid Based Nurs 2012; 9: 100-108.

10. Gao J, Zheng P, Jia Y, et al. Mental health problems and social media exposure during COVID-19 outbreak. PLoS One 2020; 15: e0231924.

11. Hadiseh F, Somayeh A, Seyedpour L, et al. Application of social networks in the field of health. Annual Student Research Congress, May 13, 2016, Ardabil, Iran.

12. Khalilai L. Students' use of social networks. Human Interaction and Information 2015; 2: 61-73.

13. Khasawneh Al, Humeidan AA, Alsulaiman JW, et al. Medical students and COVID-19: knowledge, attitudes, and precautionary measures. A descriptive study from Jordan. Front Public Health 2020; 8: 253.

14. Lifang L, Qingpeng Z, Member IEEE. Characterizing the propagation of situational information in social media during COVID-19 epidemic: a case study on Weibo. IEEE Transactions on Computational Social Systemes 2020; 7.

15. Lima DL, Lopes MAAAM, Brito AM. Social media: friend or foe in the COVID-19 pandemic? Clinics 2020; 75: e1953. 
16. Mahasti Jouybari L. The role of social media in self care behaviors. National Conference on Health Promotion Strategies and Challenges with Self-Care. Iran, Mazandaran, Sari October 2014.

17. Meşe C, Aydın GS. The use of social networks among university students. Educational Research and Reviews 2019; 14: 190-199.

18. Mousavi SJ, Shekasteh P, Aminda AE. Study of the frequency and pattern of using social networks in medical students. J Mazandaran Univ Med Sci 2019; 29: 146-152.

19. Nikbakht-Nasrabadi A, Ghiyasvandian S, Madani H. The role of mass media and social media in enlightening, reducing or increasing the concern and fear of patients. IJCA 2019; 1: 46-47.

20. Nández G, Borrego A. Use of social networks for academic purposes: a case study. The Electronic Library 2013; 31.

21. Oberiri DA, Bahiyah O. Fake news and COVID-19: modelling the predictors of fake news sharing among social media users. Telematics and Informatics 2021; 56: 101475.

22. Sahni H, Sharma H. Role of social media during the COVID-19 pandemic: beneficial, destructive, or reconstructive? Int I Acad Med 2020; 6: 70-75.

23. Samiei M. Social media and its role in the exchange of knowledge between digital protection specialists based on the honeycomb model. Epistemological studies. First year. Fall 2015; 4.

24. Taghvaei Yazdi M, Chitsaz C. The relationship between social networks and students' social health. Quarterly Journal of Information and Communication Technology in Educational Sciences 2016; 7: 97-99.

25. Viet-Phuong L, Thanh-Hang P, Toan Manh H, et al. Policy response, social media and science journalism for the sustainability of the public health system amid COVID-19 outbreak: The Vietnam lessons. Social Public Health System and Sustainability 2020; 2931.

26. Zarei J, Dastoorpoor M, Jamshidnezhad A, et al. Regional COVID-19 registry in Khuzestan, Iran: A study protocol and lessons learned from a pilot implementation. Inform Med Unlocked 2021; 23: 100520. 